EDITORIAL

\title{
Medical Education Amidst a Pandemic: Possibilities, Pitfalls and Way-Outs
}

\section{Gominda Ponnamperuma}

Correspondence to: Professor, Department of Medical Education, Faculty of Medicine, University of Colombo, Sri Lanka. Email: gominda@medarc.cmb.ac.lk, ORCiD: $0000-0003-0023-6550$

The pandemic caught us unprepared! Teaching, learning and assessment that we were used to were no longer available. The education world had to contend with a new normal with social distancing. E-learning was the only answer that the world knew. However, elearning was something that medical education had not considered as the sole mode of delivery. What follows is a brief discourse on how medical education responded to the pandemic, what has been learnt and what needs to be done to face the future more confidently.

Perhaps the easiest to adapt to the remote mode of delivery was the theory-based teaching and learning. Basic and para-clinical sciences could deliver teaching and learning with relative ease using the learning management systems and video conferencing technology. Since there was almost no time to plan and prepare when the pandemic struck, many teachers and institutes ran their face-to-face lessons unchanged, using the new-found video conferencing applications. Now that this has all happened, we need to take stock. Is conducting a face-to-face lesson using a video conferencing tool, legitimate e-learning? E-learning is broadly-defined as learning delivered using electronic technology, usually the internet.' In this sense, holding a camera to a face-to-face lesson and transferring the recording to the learner, real-time or asynchronously, may qualify to be called e-learning. However, in educational terms, was the impact of learning the same as face-to-face learning? Can we video a drama and call it a film? Or is it still a drama now delivered via video technology? Videoing a face-to-face lesson is like videoing a drama. The educational benefits of a face-toface session can never be delivered to the same extent through e-learning unless we plan to make changes to its delivery through the e-platform. Educational technology and instructional material development are specialised fields to ensure that e-learning enhances the educational benefits of face-to-face learning. So, if we are to conduct the same face-to-face session with enhanced educational value through e-learning, then we need to stop videoing the face-to-face session, go back to the drawing board and plan the lesson from the scratch to suit the new delivery mode. For instance, given the relative ease of online delivery of pre-reading material and breaking a class into virtual groups through video conferencing technology, are 'flipped classrooms' a more conducive approach to promote student engagement through e-learning? ${ }^{2}$

When compared with the online delivery of theory, the electronic delivery of clinical learning is seemingly more problematic. However, much can be done with presentday technology. Since face-to-face encounters are illadvised during a pandemic, clinical training needs implementation in the simulated settings. With the presently available video-conferencing and online learning technology, it is easy to figure out how history taking can be practised in a simulated environment using simulated and/or virtual patients. It is the training in clinical skills and clinical procedures that is more challenging to deliver remotely. That said, even within clinical skills, training the eye (i.e., observation) and the ear (i.e., auscultation) can be at least accomplished to an extent using the online delivery modes. For example, with suitable clinical photographs and videos, delivered online using a learning management system, training the eye is possible. Likewise, training the ear is also possible, for example, using audio records of lung sounds and heard sounds. It is the clinical skills related to the hand (i.e., palpation and percussion) that is severely challenged by the pandemic. For that too, haptic technology offers virtual, augmented and mixed reality solutions. ${ }^{3,4}$ However, the scarcity of suitable software and hardware to capture these technologies from home precludes their utility for remote use. Hence, clinical skills and practical procedures, at least for the time being, will have to be confined mostly to simulation skills centres. With the proper observation of social distancing norms, the students can be admitted in smaller batches to simulation skills centres to conduct clinical skills and practical procedures using suitable simulation models.

Conducting assessment during the pandemic gives rise to a separate set of issues. Similar to teaching and learning of theory, assessment of cognition (i.e., knowledge and application of knowledge) is possible, but not without modification. Multiple-choice questions (MCQs) and short answer questions are still an option, only if the fairness and equity of their online 
Ponnamperuma et al. Medical Education Amidst a Pandemic

delivery are assured. Not all candidates have the same hardware and software to take the tests. Even if they have, all may not have access to uninterrupted internet connectivity throughout the assessment. Also, an online test of this nature may test the integrity of the candidate as much as knowledge. Best of online proctoring technology, even with eye-movement tracking, is not considered foolproof as yet. Hence, even the institutions which possess such technology prefer bringing the candidates to the institution to deliver the online examination, under strict pandemic precautions. This way, they manage to alleviate the security concerns of online assessment, while harnessing its advantages such as paperless and contactless delivery, automated marking, instantaneous post-exam analysis, etc. However, if bringing the candidates to an exam hall is not an option during the pandemic, the assessment will have to be delivered to the candidate's home. Then it is more an educational problem than a technological problem. If the online MCQ or short answer question assessment assesses factual recall, then the same test security concerns may arise. Hence, the assessment method needs tweaking to test more higher-order thinking than pure recall. Higher-order thinking questions could be a viable option if coupled with other measures, such as tight timing of answers, not letting the candidate return to already attempted questions and appropriate online proctoring. However, these questions still do not overcome the equity issues like poor connectivity, substandard devices used by the candidates to access the exam, etc. Hence, many institutions have resorted to other methods of assessment rather than tweaking the existing assessment methods. Two such other assessment methods are open book exams and online assignments. ${ }^{5,6}$ These two methods also pose more of an educational challenge, as opposed to a technological challenge, to the examiner. The question design in both these methods calls for the construction of higherorder thinking questions so that the candidates cannot reproduce an answer from another source. Instead, the candidate has to think anew and synthesise the answer, drawing on from a wide range of theoretical knowledge. Such questions effectively obliviate the advantages that a candidate may have in accessing other resources. However, these questions should also be timed appropriately, though may not be as stringently as the traditional online questions, to reduce the possibility of candidates getting external help. The examiners can request those candidates, suspected of receiving undue external aid, to defend their answers at an oral examination.
Similar to remote training of clinical skills, the assessment of certain skills, especially those that involve capturing of information using the eye and the ear (as opposed to the hand), is possible, provided the issues related to candidate devices and internet connectivity are standardised. If such standardisation is not possible, most institutions opt for face-to-face assessment of clinical skills using simulated situations. Simulation is preferred here, as the contact with actual patients poses a risk to both the patient and the candidate.

All these modifications and innovations, however, can rarely replace learning from the real patients. ${ }^{8,9}$ Since that is not possible during the pandemic, it is best that what is possible with the available technology is completed. Such completion serves two purposes. First, it will keep the students occupied and in touch with their learning. Second, when the remotely possible learning and assessment are covered, there would be less pressure on both the students and teachers for post-pandemic catch-up activities.

In conclusion, the COVID-19 pandemic has opened doors to a fresh era in education. The fact that postCOVID education will never be the same that it was argues well for the future. By the end of the pandemic, educators would have perfected ways of enhancing face-to-face learning with appropriate and judicious use of technology. That is leaping several decades into the future. If this is to happen, however, we need to bust a ubiquitous myth. That is the myth that considers all elearning solutions lie in technology. Teaching, learning and assessment during and after the pandemic are not a technology problem. They are an educational problem which requires educational solutions.

\section{REFERENCES}

1. Moore JL, Dickson - Deane C, Galyen K. e - Learning, Online Learning, and Distance Learning Environments: Are They the Same? Internet Higher Educ 2011; 14:129-35. doi.org/10.1016/i.iheduc.2010.10.001

2. W Wu, JSC Hsieh, Jie - Chi Yang. Creating an online learning community in a flipped classroom to enhance efl learners' oral proficiency. J Edu Technol Soc 2017; 20:142-57.

3. Yovanoff M, Pepley D, Mirkin K, Moore J, Han D, Miller S. Personalized Learning in Medical Education: Designing a User Interface for a Dynamic Haptic Robotic Trainer for Central Venous Catheterization. Proc Hum Factors Ergon Soc Annu Meet 2017; 61:6159. doi: 10.1177/1541931213601639.

4. $\quad$ ASSH Surgical Simulation Taskforce, Wright DJ, Uong J. Establishing Validity of a Comprehensive Hand 
Surgical Training and Educational Platform (STEP). J 7. Johanns B, Dinkens A, Moore J. A systematic review Hand Surg Am 2020; S0363-5023(20)30434-2.

doi:10.1016/j.jhsa.2020.07.019.

5. Eurboonyanun C, Wittayapairoch J, Aphinives P, Petrusa E, Gee DW, Phitayakorn R. Adaptation to OpenBook Online Examination During the COVID-19 Pandemic. J Surg Educ 2020:S1931-7204(20)30346-9. doi:10.1016/j.jsurg.2020.08.046.

6. Durning SJ, Dong T, Ratcliffe T, Schuwirth L, Artino AR Jr, Boulet JR, et al. Comparing Open-Book and ClosedBook Examinations: A Systematic Review. Acad Med 2016; 91:583-99. doi: $10.1097 / A C M .0000000000000977$. comparing open-book and closed-book examinations: Evaluating effects on development of critical thinking skills. Nurse Educ Pract 2017; 27:89-94. doi:10.1016/j.nepr.2017.08.018.

8. Bleakley A, Bligh J. Students learning from patients: let's get real in medical education. Adv Health Sci Educ Theory Pract 2008; 13:89-107. doi: 10.1007/s10459-006-9028-0.

9. Rowland P, McMillan S, Martimianakis MA, Hodges BD. Learning from Patients: Constructions of Knowledge and Legitimacy in Hospital-based Quality Improvement Programmes. Studies Continuing Educ 2018; 40:337-50. doi.org/10.1080/0158037X.2018.1465402 